\title{
AGE-RELATED DIFFERENCES IN LANGUAGE USE WITHIN THE MATHEMATICAL REGISTER
}

\author{
Rod E. Case* \\ University of Nevada, \\ Reno
}

\author{
Peter Cobin \\ Washoe County School \\ District
}

\author{
Gwendolyn M. Williams \\ Auburn University
}

\begin{abstract}
The struggles that learners face as they attempt to produce mathematical explanations have been widely documented from researchers working in the systemic functional linguistics tradition. The approach has been to isolate specific grammatical patterns which differ across the natural and mathematical register and then argue that these represent a source of trouble for learners. This manuscript explores the extent to which age accounts for differences in the production of explanations within the mathematical register, but does so from a cognitive linguistic tradition.

Data was collected over three weeks from 50 students, 30 boys and 20 girls in five different classrooms. A Chi-Square test of independence demonstrated age-related differences in the use of six different grammatical patterns within the mathematical register. The larger argument is made that producing explanations within the mathematical register relies more on the strategic use of multiple grammatical patterns and semantic forms than the mastery of a single grammatical pattern.
\end{abstract}

Key words: Academic language, functional language, elementary math

\section{INTRODUCTION}

Past research into the language use within the mathematical register has relied on the analysis of single grammatical patterns. Researchers such as Pimm (1987) and Veel (1999) drew heavily on Halliday's (1978) work on Systemic Functional Linguistics (SFL) and discussion of the contrasts between the language of the natural register and of the mathematical register and described a wide range of syntactic and semantic differences. Examples included technical vocabulary, dense noun phrases, being and having verbs, conjunctions with technical meanings and implicit logical relationships,

\footnotetext{
* Corresponding author: Rod E. Case, College of Education, University of Nevada, Reno 89557 Email: rcase@unr.edu
} 
multiple symbolic notations, oral language, written forms and graphs and visual displays. Later, MacGregor (2002), Sfard and Lavie (2005) and Lemke (2003) focused on how specific grammatical differences between the two registers contribute to difficulties that students have with using the mathematical register.

While this research has aptly described the lexico-grammatical differences between the two registers, there are at least two questions left open. First, research into the question of what age students begin using language within the mathematical register is conflicting. Some findings suggest that learners may be capable of producing language within the mathematical register as young as four-years old (Sfard and Lavie, 2005) while other research suggests that students continue to struggle into young adulthood MacGregor (1991, 2002). Second, there is a question of research methods. To date, researchers have limited their work to the analyses of how specific grammatical patterns within the mathematical register cause difficulties for learners as they try to produce mathematical explanations. The approach, while valuable, is at odds with research by Langacker (1987, 2008), Lakoff and Nunez (1999) and Tomasello and Rakoczy (2003) which suggests that successfully producing explanations within a given register relies more on the strategic use of multiple grammatical patterns and semantic forms than mastery of a single grammatical pattern.

This study answers those two calls for research in the literature. Data from 50 students (K-6) and 100 math prompts is used to explore age-related changes in the use of language within the mathematical register across grades 1-6. Second, a cognitive linguistic analysis of how multiple grammatical forms are used strategically within the mathematical register is proposed as an alternative to contemporary research on the use of language within the mathematical register by MacGregor (1991, 2002), and Schleppegrell \& O'Hallaron (2011) and Sfard and Lavie (2005) which emphasizes the use of single grammatical patterns within the mathematical register.

\section{LITERATURE REVIEW}

Research into the language of math draws on SFL theory and provides the background/basis of research into academic language. For more than 20 years, researchers have identified the ways in which Halliday's (1978) SFL can provide insights into linguistic repertoire that students must have to succeed in mathematics (e.g., Lemke, 2003; MacGregor, 1993; O’Halloran, 1999, 2000; Pimm, 1987; Veel, 1999). Two areas of research into the language of mathematics from an SFL perspective are prevalent. These include a focus on the grammatical patterning in math (e.g., See Schleppegrell [2007] for full review of the research) and the ways in which mathematics employs multiple semiotic systems to create meaning (e.g., O'Halloran, 1999, 2000, 2003).While both areas provide a highly accurate mapping between linguistic 
form and use, research into grammatical patterning is the least explored. This review addresses the research into grammatical patterning and argues that an alternative unit of analysis, the symbolic unit, placed within the cognitive linguistic tradition can provide a useful tool for both the researcher and the teacher.

Research in SFL and the language of mathematics draws upon the concepts of register (Halliday, 1978), genre (Christie \& Derewianka, 2008) and to a lesser extent academic language (Unsworth, 2000; Schleppegrell, 2011; Schleppegrell \& de Oliveira, 2006; Aguirre-Munoz, Park, Amabisca, \& Boscardin, 2008). Halliday's (1978) definition of register is below.

\section{A set of meaning that is appropriate to a particular function of language, together with the words and structures which express these meanings. We can refer to a 'mathematics register, in the sense of the meanings that belong to the language of mathematics (the mathematical use of natural language, that is not mathematics itself), and that a language must express if it is being used for mathematical purposes (p. 195).}

Importantly, while the ways in which specific lexical and grammatical patterning are realized within the mathematics register are very specific, e.g., differences between proportional and difference comparison described in MacGregor (2002), the emphasis is on describing their use across registers and as "resources for making meaning" (de Oliveira \& Chang, 2011, p. 257) rather than isolating specific linguistic trouble spots for students. The language of mathematics is, according to Halliday (1978), "appropriate to a particular function of language, together with the words and structures which express these meanings" (p. 195) and so any analysis belongs within a larger discussion of register and discourse. To Halliday (1978), describing mathematics as a register highlights the ways in which language is used in mathematics and calls on students to acquire more than new vocabulary but also new "modes of argument" (p. 196) and ways in which elements of syntax and discourse must be organized and reorganized to solve specific problems and establish different purposes for writing.

For the last twenty years, researchers have identified ways in which specific lexical and grammatical patterns differ between mathematics texts or classroom texts and natural language use and identified them as a source of confusion for students (e.g., Lemke, 2003; MacGregor, 1993, 2002). Semiotic and grammatical patterns which separate language use in mathematics from everyday use of language draw on work by O'Halloran (1999, 2000, 2003); Lemke; Pimm (1987); Schleppegrell (2007); and Veel (1999) and summarize these features. At the grammatical level, patterns include technical vocabulary, dense noun phrases, being and having verbs, conjunctions with technical meanings and implicit logical relationships. There are also meanings 
that are formed through multiple symbolic notations, oral language, written forms and graphs and visual displays. Lemke explained that the register of the mathematics grew out of everyday language. According to Lemke, words and meanings grew as part of the natural "semantic reach of natural language into new domains of meaning" (217).

In a study of 68 pre-service teachers on how language is used to indicate comparisons, MacGregor (2002), for instance, finds that just eight students used the comparative form accurately, 6 times as many dogs as cats (p. 83). The remainder relied on either awkwardly constructed forms, e.g., The number of dogs are 6 times as the cats (p. 83) or, more often, what MacGregor terms the composite form in which students wrote, There were six times more dogs than cats (p. 83). While MacGregor does not tie the students' choice of phrasing to mathematical proficiency, she does draw on past research (MacGregor, 1991; MacGregor \& Stacey, 1993) to argue that students who rely heavily on natural language to formulate mathematical ideas often come to inaccurate conclusions.

Research by Sfard and Lavie (2005) extends the dichotomy between the natural register and mathematics register. Their study provides data from detailed transcripts and observation of two four-year olds as they describe mathematical concepts to their parents. That research found that a part of the movement from a natural register to a mathematics register requires the objectification of language. As children grow, according to Sfard and Lavie, they first learn to use language which links numbers to concrete referents. This can be seen in a classroom in which students count blocks and the number three refers to three blocks. The next step occurs when students can use grammatical patterns in which numbers are abstract entities. For instance, Three is greater than one would not be linked readily using a one-to-one mapping of blocks to numbers because of the abstract use of the adverb greater.

In conclusion, previous research on the language of mathematics from an SFL perspective has emphasized ways in which students move from the register of natural language to the register of mathematics. To that end, researchers have isolated individual grammatical patterns within the mathematics register and tied them to the problems students have with producing explanations within mathematics, and, by extension, arguing that language and mathematical proficiency go hand in hand. To date, research into the question of what age students begin using grammatical patterns within the mathematics register has been mixed, suggesting that students may engage in using language as part of the mathematics register as young as fouryears old (Sfard \& Lavie, 2005) while others still struggle into young adulthood (MacGregor, 2002). Also, research methods have been limited to analysis of a single grammatical pattern within the mathematics register. Research on how and what particular grammatical patterns cluster together as 
part of the strategic use of language within the mathematical register has yet to be conducted.

\section{SYMBOLIC UNITS AND COGNITIVE LINGUISTICS}

Research into cognitive linguistics provides a strong foundation for examining the strategic use of language within the mathematical register. A central tenet within cognitive linguistics is the close pairing between linguistic structures, meaning and cognition (Langacker, 1987, 2008; Lakoff \& Nunez, 1999; Tomasello, 1992; Tomasello \& Rakoczy, 2003). Langacker (1987) explains that the basic organizing units of language are the pairings of semantic and syntactic structures. Syntactic structures combine to form units and then larger forms of semantic structures. Making divisions between grammar and the lexicon of a language disrupts the connections between grammar and meaning. The ability to make use of structures in a language moves from a declarative knowledge of the language, which requires the speaker to puzzle over explicit knowledge of the rules of language before production, to a procedural knowledge of the language in which knowledge of grammatical and semantic forms have been internalized and can be acted on with a high level of automaticity.

A unit is described as a structure that a speaker has mastered at a level of proficiency that has reached automaticity. It is not necessary for the speaker to devote specific cognitive resources to its production. As an example, a learner who is mastering the genre of an explanation as part of a math class struggles, stopping at each sentence to reflect on the model and the next possible step to take in the paragraph. In time and with practice, the learner makes the connection between the grammatical patterns each sentence presents and its meaning. The result is the connection between lexis and grammatical form, which Langacker (1987) terms, symbolic unit. Smaller symbolic units, such as morphemes or simple grammatical structures, form to combine larger structures, such as words and larger grammatical structures and, eventually, rhetorical structures. The ability to combine multiple syntactic structures is predicated upon the learner having reached a high level of automaticity.

The task of writing a short paragraph, for example would require a student to assemble a number of smaller symbolic units, e.g., sentences and phrases, and then strategically combine with additional symbolic units. The task of creating the paragraph for the competent writer is a process of strategically combining and recombining multiple symbolic units, e.g., particular grammatical structures and selected vocabulary, into a single desired message. The same paragraph may be written using multiple combinations of syntactic structures or vocabulary items, the only limitation being the skill of the writer. 


\section{METHOD}

Data was collection from 50 students, 30 boys and 20 girls in five different classrooms. Twenty-five students were grades K-3, and 25 were grades 4-6. Teachers followed their regular math curriculum, although a few had incorporated math journals into their instruction before the program began, so they added math journals to their teaching. Sixteen teachers participated from 8 different schools. Four schools were Title I schools and had 24 students, and 4 schools were non-Title I and had 26 students.

Data was collected over three weeks. Researchers met with the five teachers and provided an overview of the research. Teachers were asked to require participating students the task of creating math journals to accompany their present math assignments. Each student was given a different piece of paper which had a blank space to complete their journal entry. Math questions varied by grade level, but teachers in each grade level used the same texts with the same questions. Thus, all first graders, for instance, completed the same questions, and all second graders completed the same questions. The selection of the questions was guided by the local school district math standards. Sample questions are below (See Table 1).

\section{Table 1 Sample Questions used for Data Collection}

\section{Grade Question \\ $123+14=$ ? Tell what you did.}

2 How much is three dimes and two nickels? How did you get your answer?

3 The library has 383 mystery books and 247 sports books. How many more mystery books are there? Tell why your answer makes sense.

$4 \quad$ No journals used for analysis.

$5 \quad$ Shania had a length of wood $14 \frac{3}{4}$ feet long. She wanted to us it for fence posts that were $4 \frac{1}{2}$ feet long.

A) How many fence posts can she cut from one piece of wood?

B) How much wood will be left over?

A garden is in the shape of a rectangle is $\mathrm{x}$ feet wide and $\mathrm{x}+3$ feet long. The perimeter of the rectangle is 36 feet. Is it possible that the value of $\mathrm{x}$ is 8 ?

Next, since there was no instrument that could separate out journal entries that contained mathematical register usage, it was necessary to create one. Two bodies of research informed the creation of the instrument. First, 
research into the ways in which single grammatical patterns contribute to the mathematical register by Schleppegrell (2014), O'Halloran (1999, 2000, 2003), Lemke (2003), Pimm (1987) and Veel (1999) was included. Second, the genre of explanation was chosen as the benchmark to examine students' use of language within the mathematical register, as it was consistent with the expectations students were given when asked to complete their math journals. According to Christie and Derewianka (2008), an explanation requires more than relating a loose sequence of events. The real goal of explanation is to explain a particular phenomenon---how something works. In the case of math journals, it would require explaining the reasoning or thinking behind how a problem was solved. An explanation typically begins with a statement of the phenomenon, and then moves on to an explanation and ends with a concluding remark.

Following the work of Christie and Derewianka (2008), an instrument was developed with the purpose of separating journal entries which provided a mathematical explanation versus those that did not (See Table 2).

\section{Table 2 Explanation Questionnaire}

1. Does the response contain an account of how the problem was solved?

2. Does the response contain a rationale or explanation for the student's reasoning?

3. Did the student solve the problem?

The instrument included three statements. Question one determined whether or not the participant gave an account of the how the problem was solved; question three asked if there was a rationale, and the final question asked whether or not the problem was solved. Each journal entry was read by the researchers twice and marked individually. Researchers did not know the age level of the students or their identities. As one the researchers knows the participants in the study, all entries were typed to make it impossible to detect the identity of the participants. Journal entries which received an affirmative mark on each statement from all three researchers were accepted as satisfactory explanations. The researchers rejected any entries that they did not agree upon. Researchers determined that a total of 23 journals in the primary (K-3) and 14 in the intermediate group (4-6) met the criteria.

Next, a linguistic analysis of all of the journal entries was conducted to determine the most frequently occurring grammatical patterns at the sentence level. Initially, a list of grammatical patterns from Christie and Derewianka (2008) was used in the research instrument to examine the students' work. These included generalized non-human participants, cause-and effect relationships, action verbs and the passive voice. 
Table 3 Symbolic Unit for Instruction Genre

\begin{tabular}{|c|c|c|}
\hline Symbolic Unit & Definition & Example \\
\hline \multirow[t]{2}{*}{ Intent/Purpose } & goal, desire & $\begin{array}{l}\text { She's trying to find her } \\
\text { money. } \\
\text { Event) }\end{array}$ \\
\hline & & $\begin{array}{l}\text { We wanted to design a } \\
\text { robot that puts garbage } \\
\text { out all by itself. } \\
\text { (Intention-Event- } \\
\text { Manner) }\end{array}$ \\
\hline Unknowns & $\begin{array}{l}\text { information that is } \\
\text { partially unknown or } \\
\text { unspecified }\end{array}$ & $\begin{array}{l}\text { Orange juice is healthy } \\
\text { because it has vitamins. } \\
\text { (Cause-Properties) }\end{array}$ \\
\hline Reason/Cause & $\begin{array}{l}\text { reason or cause for an } \\
\text { outcome }\end{array}$ & $\begin{array}{l}\text { The substitute made us } \\
\text { write all day. (Cause- } \\
\text { Participant-Event- } \\
\text { Time }\end{array}$ \\
\hline Result & $\begin{array}{l}\text { effect, outcome, } \\
\text { consequences, etc. of an } \\
\text { action }\end{array}$ & $\begin{array}{l}\text { I added and I got twenty- } \\
\text { three. (Result-Event) }\end{array}$ \\
\hline Condition & $\begin{array}{l}\text { Instances, etc. when } \\
\text { certain properties apply } \\
\text { or events happen }\end{array}$ & $\begin{array}{l}\text { I didn't eat breakfast so } \\
\text { now I am hungry. } \\
\text { (Result-Event- } \\
\text { Cause-Property) }\end{array}$ \\
\hline \multirow[t]{3}{*}{ Instructions } & $\begin{array}{l}\text { Steps to guide someone } \\
\text { through a process }\end{array}$ & $\begin{array}{l}\text { If you're sick you have to } \\
\text { stay home. (Condition- } \\
\text { Property-Event- } \\
\text { Commitment-Location) }\end{array}$ \\
\hline & & $\begin{array}{l}\text { Never try this experiment } \\
\text { unless there is an adult } \\
\text { watching. (Condition-- } \\
\text { Events-Property) } \\
\text { Now I add the flour, and } \\
\text { then I'm going to mix it. } \\
\text { (Instructions- } \\
\text { Sequence-Events) }\end{array}$ \\
\hline & & $\begin{array}{l}\quad \text { Use your finger to } \\
\text { make a space and then } \\
\text { write the next word. } \\
\text { (Instructions- } \\
\text { Sequence-Events- } \\
\text { Intention-Manner) }\end{array}$ \\
\hline
\end{tabular}


After further research, however, it became clear that the participants were using grammatical patterns that were not indicated by Christie and Derewianka (2008).

These were tallied and added to the research instrument. The most prevalent was participant/action (Noun/Verb) combinations and sequences, but they were dismissed as every sentence will have a noun and verb combination and every explanation used reference. Also, all but one of the entries used action verbs, and so this category was dismissed as well. Finally, none of the entries included the passive voice, so this was dismissed. This left cause/effect relationships from the Christie and Derewianka (2008) text and five additional grammatical patterns from the data (See Table 3).

Next, definitions and examples of each symbolic unit were developed (See Table 3).

Table 4 Frequency Table for Primary and Intermediate Students

\begin{tabular}{|c|c|c|c|}
\hline & & & Total \\
\hline & Primary & Intermediate & \\
\hline Exhibited & & & \\
\hline Exhibited Count & 23 & 14 & 37 \\
\hline Expected Count & 25.9 & 11.1 & 37.0 \\
\hline Adjusted Residual & -2.0 & 2.0 & \\
\hline Table 4 (cont.) & & & \\
\hline Frequency Table fo & rimary and & mediate Students & \\
\hline & & & Total \\
\hline & Primary & Intermediate & \\
\hline$\overline{\text { Absent }}$ & & & \\
\hline Absent Count & 12 & 1 & 13 \\
\hline Expected Count & 9.1 & 3.9 & 13.0 \\
\hline Adjusted Residual & 2.0 & -2.0 & \\
\hline Total Count & 35 & 15 & 50 \\
\hline Expected Count & 61.0 & 25.0 & 86.0 \\
\hline
\end{tabular}

Examples were taken from the learners' journal entries. Definitions were drawn broadly from work by Langacker $(1987,2008)$, Lakoff and Nunez (1999), and Tomasello and Rakoczy (2003). The top six symbolic units were as follows: cause (32), results (29), intentions (19), unknowns (16), conditions (14) and instructions (13). These units were then placed into a $2 \mathrm{X} 2$ Chi- 
Square. A Pearson's Chi-Square was calculated as well as a Fisher's Exact test. To control for validity, each entry was checked independently by two researchers and then compared (See Table 4). When agreement could not be reached, the selected journal entry was discarded.

\section{FINDINGS}

A Chi-Square, $2 \times 2$ test of independence was conducted, performance (exhibited versus absent) by level (primary versus intermediate). The chisquare was significant, $X^{2}(1, N=50,=4.163, p<.041$. The phi coefficient was .289 , indicating a medium effect size. Because the expected frequency of one cell fell below 5, a Fisher's Exact Test was used. The one-tailed significance was $p=.039$. By inspecting Table 3 , it is apparent that significantly more intermediate than primary students exhibited the symbolic unit.

\section{DISCUSSION}

Researchers have attributed the difficulty students face in producing explanations of their mathematical thinking to the unique and specific ways in which syntax and vocabulary are realized in the mathematics register in comparison with the natural register (e.g., Lemke, 2003; MacGregor, 1993, 2002; O'Halloran, 1999, 2000; Pimm, 1987; Veel, 1999). Specific grammatical patterns that differ between the two registers are thought to be the source of difficulty, but few researchers have studied the extent to which age may play a part in this question. This study examined the math journals of 50 students across six different grammatical patterns. Findings suggest agerelated differences in the use of six different grammatical patterns within the mathematics register. The contributions of these findings to the current research into SFL and the language of math are discussed below.

First, at a methodological level, the decision to survey the students' work for the most common grammatical patterns within the mathematical register is unique. Past research has relied heavily on isolating a single grammatical pattern for analysis which differs from the natural register and exploring ways in which that pattern represents a point of difficulty. These are summarized in work by Lemke (2003), Pimm (1987) and Veel (1999) and discussed in related but more current research and writing by Schleppegrell (2014) and O'Halloran $(1999,2000,2003)$. This research did not compare the registers of the natural register and the mathematical register. Rather, drawing on work by Christie and Derewianka (2008), this research examined how multiple grammatical patterns within the mathematical register vary across age groups. Five of the six grammatical patterns were not indicated by Christie and Derewianka as significant within an explanation. The reason for this may be 
that while Christie and Derewianka's work provides a linguistic overview of an explanation, it is not specific to the mathematical register.

The data suggested that producing explanations within the mathematical register is more dependent on the strategic use of multiple grammatical patterns rather than a single grammatical pattern. This is in part suggested by the finding that the selected essays exhibited all six grammatical patterns at a statistically higher level, but it is also suggested by a close reading of the entries. The example below is from a fourth grade student who was asked to interpret a graph in which each tree on the graph represented four new trees that were planted in the forest. The students was asked to calculate how many trees he would have to place on the graph if he wanted to show that he planted 16 trees. He presents the following.

\section{I know (commitment) answer 6 is correct (result, property) because (reason) I looked at the key (event, location) which looked like this: (specification) So I counted by 4 (event, sequence, manner) until I got to 16 (condition, result) and kepted track (event, sequence) of how many numbers (unknown) I said (event) with my fingers. (manner). Then I looked at my answer (event, sequence, location) and found 4 (event, sequence, result) I would draw 4 trees (event, commitment) because (reason) each tree stands for 4 votes (property)}

Notice how the student's success is dependent upon the strategic use of multiple grammatical patterns. Here, the student employs four symbolic units (underlined) in his answer. Each symbolic unit strategically moves the student closer to the answer. The first symbolic unit, result and reason, allow the student to identity the goal or end-result of his analysis, thus orienting the reader towards his objective. The next symbolic unit, result, resolves the question of how he interpreted the key. This sets the stage for the series of calculations that he performed in which he created four groups of four. The third symbolic unit, result, signals that he has concluded this stage and reports his results. Finally, he concludes his paragraph with a sentence summarizing his calculations. The final symbolic unit, reason, signals that he has checked his answer. The second example is from a low third grade student. Here, the student was asked to calculate how many balls will be needed if two classes of students wish to play. One ball will be needed for every two students. One class has 20 students. The other has 24 . The student's response was as follows: "I drew 10 balls (event) and then I drew twelve balls (event, sequence) and I added them together (event, sequence) and I got 22 (event, sequence, result)."

This particular example demonstrates what happens when a student relies on a single grammatical pattern within the mathematical register. Missing is an introductory statement in which the reader learns the goal of the task, which is to find how many balls will be needed if there are 44 students and 
one ball for every two students. In the advanced example, this was solved by using a result and reason. Instead, this student begins with the calculations, not informing the reader that the calculations are part of a larger problem which involves division, "and then I drew twelve balls (event, sequence) and I added them together (event, sequence)." The problem is resolved, "and I got 22 (event, sequence)" with one symbolic unit.

Finally, drawing on a $2 \times 2$ Chi-Square analysis, findings from this study demonstrate age-related differences in the production of six symbolic units. The results of this research found that students as young as the fourth grade were beginning to use language within the mathematical register. Only limited research has explored the question of age-related differences of language use in the mathematical register. This finding contributes to research by MacGregor (2002) which suggests that pre-service teachers struggle to use the comparative form accurately and a study by Sfard and Lavie (2005) that found that students as young four years old are able to describe mathematical concepts to their parents and thereby participate in the mathematics register. Moreover, the examples above illustrate the distinct differences between students who have begun to write and use language within the mathematical register, a fourth grader in this case, and students who do not, a third grader, yet still are able to solve the problem. From a cognitive linguistic perspective (e.g., Langacker, 1987, 2008; Lakoff \& Nunez, 1999; Tomasello, 1992; Tomasello \& Rakoczy, 2003), the differences in their explanations would be explained by the fourth-grader's ability to not only access the specific grammatical patterns associated with the mathematical register described by Halliday (1978) but also strategically combine and recombine them in a way which advances an explanation.

This study has some limitations. The findings are limited to the exploration of a small population of elementary school students. More research is needed with larger populations over time to make any statements about the generalizability of these findings. Moreover, more research is needed among specific populations, e.g., English language learners, students with learning disabilities and ethnic minority populations, to explore the particular challenges they may or may not face. Not enough is known about age-related differences among students in middle- and senior-high where the demands of employing academic language increase and change. Nevertheless, this research represents a beginning into the exploration of how multiple grammatical patterns contribute to the mathematical genre and the role of age in producing language within the mathematical genre.

\section{REFERENCES}

Aguirre-Muñoz, Z., Park, J.-E., Amabisca, A., \& Boscardin, C. K. (2008). Developing teacher capacity for serving ELLs' writing instructional needs: A case for SFL. Bilingual Research Journal, 31, 295-322. doi: 10.1080/15235880802640755 
Bunch, G. (2006). "Academic language" in the $7^{\text {th }}$ grade: Broadening the lens, expanding access. Journal of English for Academic Purposes, 5, 284-301. doi: 10.1016/j.jeap.2006.08.00

Christie, F, \& Derewianka, B. (2008). School discourse: Learning to write across the years of schooling. London: Continuum.

Ernst-Slavit, G., \& Mason, M. (2008). Words that hold us up. Linguistics and Education, 22(4), 430-440. doi: 10.1016/j.linged.2011.04.004

Freeman, Y.S. \& Freeman, D. E., (2009). Academic Language for ELLs and Struggling Readers How to Help Students Succeed Across Content Areas. Portsmouth, NH: Heinemann.

Gottlieb, M. \& Ernst-Slavit, G. (2013). Academic language in diverse classrooms. Mathematics, grades 3-5: Promoting content and language learning. Thousand Oaks: Corwin.

Halliday, M.A.K. (1978). Language as social semiotic. The social interpretation of language and meaning. London: Edward Arnold.

Lakoff, G. \& Nunez, R. (1999). Where mathematics comes from: How embodied mind brings mathematics into being. New York: Basic Books.

Langacker, R. W. (1987). Foundations of cognitive grammar. Stanford: Stanford University Press.

Langacker, R. W. (2008). Cognitive grammar: A basic introduction. New York: Oxford University Press.

Lemke, J. L. (1989). Making text talk. Theory into Practice, 28(2), 136-141. doi $10.1080 / 00405848909543392$

Lemke, J. L. (2003). "Mathematics in the middle: Measures, picture, gesture, sign and word". In Anderson, M., Saenz-Ludlow, A., Zellweger, S. \& Cifarelli, V., (Eds.). Educational Perspectives on Mathematics as Semiosis: From Thinking to Interpreting to Knowing (pp. 215-234). Ottawa: Legas Publishing

MacGregor, M., \& Stacey, K., (1993). Cognitive modeling underlying students' formulation of simple linear equations. Journal for Research in Mathematics Education, 24(3) 217-232.

MacGregor, M. (2002). Using words to explain mathematical ideas. Australian Journal of Language and Literacy, 25(1), 78-88. Retrieved from http://www.alea.edu.au/resources/australian-journal-of-language-and-literacyajll/australian-journal-of-language-and-literacy-ajll

O'Halloran, K. L. (1999). Towards a systemic functional analysis of multisemiotic mathematics texts. Semiotica, 124(12), 1-29. doi: 10.1515/semi.1999.124.1-2.1

O'Halloran, K. L. (2000). Classroom discourse in mathematics: A multisemiotic analysis. Linguistics and Education, 10(3), 359-388. doi: 10.1016/S08985898(99)00013-3

O'Halloran, K. L. (2003). Educational implications of mathematics as a mutisemiotic discourse.

In M. Anderson, A. Saenz-Ludlow, S. Zellweger \& V. V. Cifarelli (Eds.), Educational perspectives on mathematics as semiosis: From thinking to interpreting to knowing (pp. 185-214). Brooklyn, NY: Legas.

Pimm, D. (1987). Speaking mathematically: Communication in mathematics classrooms. London: Routledge \& Kegan Paul.

Schleppegrell, M. (2004). The language of schooling: A functional linguistics perspective. Mahwah, NJ: Lawrence Erlbaum. 
Schleppegrell, M. J. (2007). The linguistic challenges of mathematics teaching and learning. Reading and Writing Quarterly, 23, 139-159. doi: $10.1080 / 10573560601158461$

Schleppegrell, M. J. (2011). Supporting disciplinary learning through language analysis:

Developing historical literacy. In F. Christie \& K. Maton (Eds.), Disciplinarity:

Functional linguistic and sociological perspectives (pp. 197-216). London: Continuum

Schleppegrell, M., \& de Oliveira, L. C. (2006). An integrated language and content approach for history teachers. Journal of English for Academic Purposes, 5, 254268. doi:10.1016/j.jeap.2006.08.003

Schleppegrell, M. J., Greer, S., \& Taylor, S. (2008). Literacy in history: Language and meaning. Australian Journal of Language and Literacy, 31, 174-187. Retrieved from

http://www.alea.edu.au/resources/australian-journal-of-language-and-literacyajll/australian-journal-of-language-and-literacy-ajll

Schleppegrell, M. J., \& O'Hallaron, C. L. (2011). Teaching academic language in L2 secondary settings. Annual Review of Applied Linguistics, 31, 3-18. doi: $10.1017 / \mathrm{S} 0267190511000067$

Sfard, A., \& Livie, I., (2005). Why cannot children as the same as what grown-ups see as different?-Early numerical thinking revisited. Cognition and Instruction 23(2), 237-309.

Tomasello, M., (1992). The social bases of language acquisition, Social Development, 1, 67-87. doi: 10.1111/j.1467-9507.1992.tb00135.x

Tomasello, M., \& Rakoczy, H. (2003). What makes human cognition unique? From individual to shared collective intentionality. Mind and Language 18(2), 121-147. doi: 10.1111/1468-0017.00217

Unsworth, L. (Ed.). (2000). Researching language in schools and communities: Functionallinguistic perspectives. London: Cassell.

Veel, R. (1999). Language, knowledge and authority in school mathematics. In F. Christie (Ed.), Pedagogy and the shaping of consciousness: Linguistic and social processes (pp. 185-216). London: Continuum. 